\title{
Measuring Household Food Security Index for High Hill Tribal Community of Nagaland, India
}

\author{
Aatish Kumar Sahu*, Zhopnu Chüzho, Sanjoy Das \\ Department of Agricultural Economics, SASRD, Nagaland University, Medziphema, Nagaland, India \\ *Corresponding author: aatishksahu@gmail.com
}

\begin{abstract}
With limited literature available on food security of tribal people, the study focused on the methodology of measurement on food security index of the tribal people residing in high altitude remote rural villages of Phek district of Nagaland, a state in north eastern part of India. Six indices on household food security developed and elaborated by international agencies were adopted with due modification to suit the study region. A multi-stage sample survey on rural households was conducted with pre tested structured interview schedule in Phek district during November 2016 for getting information on socio-economic aspects, food basket, weekly consumption of food groups, weekly expenditure on food items etc. From the information obtained four components of food security namely Household Diet Diversity Score, Food Consumption Score, Coping Strategy Index, Self Assessed Food Security Scale, and two components of household food insecurity namely Household Hunger Scale and Household Food Insecurity and Access Scale has been developed. Overall Food Security Index (FSI ${ }_{\mathrm{P}}$ ) was obtained from the algebraic relation on above mentioned six indicators. The result showed that there was high and significant correlation of indicators like $\operatorname{HDDS}_{\mathrm{P}}(\mathrm{r}=0.36), \mathrm{HHS}_{\mathrm{P}}(\mathrm{r}=-0.57), \mathrm{CSI}_{\mathrm{P}}(\mathrm{r}=0.58), \mathrm{HFIAS}_{\mathrm{P}}(\mathrm{r}=-0.43)$ and $\mathrm{SAFS}_{\mathrm{P}}(\mathrm{r}=$ $0.40)$ with FSI $_{p}$. Socio-economic factors especially household income $(\mathrm{r}=0.226)$ and family size $(\mathrm{r}=-0.496)$ had significant correlation with FSI $_{p}$. Large family sizes were significantly lower in food security index compared with small family size households. It is concluded from the study that alternative methodology of indicators are useful to study region specific food security rather conventional generalized ones.
\end{abstract}

Keywords: food security index, tribe, nagaland, chakhesang, pochury, food basket, villages, household

Cite This Article: Aatish Kumar Sahu, Zhopnu Chüzho, and Sanjoy Das, "Measuring Household Food Security Index for High Hill Tribal Community of Nagaland, India." Journal of Food Security, vol. 5, no. 5 (2017): 155-161. doi: 10.12691/jfs-5-5-1.

\section{Introduction}

Household food security represents knowledge, availability, access and psychologically comfortable situation of a family towards food they need for a healthy living on regular basis. Phek district of Nagaland is the highest altitude district at above $2000 \mathrm{~m}$ above mean sea level in the state with relatively colder climate throughout the year. Being mountainous and hilly region with weak infrastructure like road connectivity, natural calamities like landslides, poor electricity, insurgency, frequent blockades, and low level of food production with far away daily market; it was pertinent to study food security level for the 0.17 million people mostly belonging to Chakhesang and Pochury Scheduled Tribes of India residing in the district of 2026 square kilometer of area. The land holding pattern was unique in the state with community based holding and type of occupation was more or less similar for households. The major agriculture food items produced in Phek during 2013-14 were WRC paddy (33640 t), Maize (17350 t), Soybean (2680 t), Sugarcane (10890 t), Potato (12890 t), Cabbage (20177 t), Tapioca (10195 t), Ginger (5316 t), Chilli (4123 t), Colocasia
(3265 t), Pineapple (9189 t), Orange (4575 t), Banana (9867 t), Passion fruit, Kiwi, Papaya, tea (3010 t) and many other horticultural fruits and various millets like Jowar, Barley, small millets etc [30]. In addition to crops, livestock rearing viz., piggery, poultry, rabbit, etc. are very common feature among the rural households. The Nagas have food habit of two meals at day with rice as staple starchy diet with vegetables and meat. During ceremonies, marriages and festivals, pork and beef of Mithun (a wild bovine species) are culinary delight to local tribesmen. With 58 percent of the state under forest, hunting of birds and small wild animals is widely practiced here. Nagaland is known as 'Land of Festivals' with culturally very vibrant state with variety of food items to fulfill people's food aspiration especially 'meat'. Hornbill Festival, an international tourism fest of the state showcases the traditional and culinary achievements of north eastern region of India.

The Nagaland Food Security Act (NFSA, 2013) enacted by the state of Nagaland in June 2016 with priority households and Antyodaya Anna Yojana beneficiaries covered under the Act underpins role of governance in food security (Candel, 2014). The beneficiaries were entitled for $5 \mathrm{~kg}$ of food grains (Rice and wheat) per person per month at very nominal rate of Rs. 3/- for rice 
and Rs. 2/- for wheat. In Nagaland as well as north-eastern region of India, many wild edibles and entomophagy (insect eating) food habits have been documented. Many types of insects and caterpillars are consumed as additional or recreation food type by the local tribal people. The knowledge of tribal people regarding nutritional values and medicinal properties of wild edibles (plant products as well as wild animals and birds) and various insects has immense effect on local eating behavior. Hence food security measurement for north eastern region of India needs to be understood in these aspects also. Also a say going here "Everything that moves can be taken as food" indicating food preference of local tribes being much broader and primitive.

Household food insecurity was difficult to generalize and measure as it is a dynamic issue and of multiple-dimension [33]. The conventional Household food (in)security as studied under six components viz., Food Consumption Score (FCS), Household Hunger Scale (HHS), Coping Strategies Index (CSI), Household Dietary Diversity Scale (HDDS), Household Food Insecurity Access Scale (HFIAS) and Self Assessed measure of Food Security Score (SAFS) were based on recall period and hence found unsuitable relevant for classifying tribal households. These indicators were developed by various agencies namely United Nation Food and Agriculture Organization (FAO), World Food Programme (WFP) and United States Agency for International Development (USAID) [6,10,11,22], and validated [16,17] for measuring and comparison of food security levels at larger regional levels. Approaches to food security measurement [3] followed four major pillars of food security-availability, access, utilization, and risk. Barret categorized indicators of food security into five units [4]: Dietary diversity and food frequency that includes different kind of food or food groups consumed by people in a specified region and frequency; Spending proportion on food to total household income [29] with higher proportion indicating propensity to food insecurity; Consumption behaviors measurement using Coping Strategies Index $[22,23]$ that measures food security indirectly by measuring behaviors by tracking frequency and identifying severity of behaviors during low food possession; Experiential measures like Latin America and Caribbean Food Security Scale (ELCSA) and the Household Food Insecurity Access Scale that are widely used in international contexts that combine behavioral with psychological measures [6,9]; and Self-assessment measures of food security (SAFS) is self assessment of household on their food security status. However, nutritional status of household being much broader and subsumes food security as a factor [36] was found to be difficult to assess in the region.

Each of the conventional six food security scores had respective applicability, advantages as well as disadvantages, but more prominence was observed in lacunae in recognizing community or village level of food security. This was needed especially for small and remote villages having indigenous tribes with unique traditions and food habits. So, the study was undertaken to study the six indicators developed as per local requirement of Phek district of Nagaland, its relevance and measure households' Food Security Index.

\section{Research Methodology}

The food security status of rural households of Phek district of Nagaland was empirically studied during November 2016 to February 2017 using cross-sectional survey. For the study, Phek district was purposively selected with two blocks namely Kikruma and Pfutsero out of five existing blocks were randomly sampled. From each block two villages were randomly selected, thus four villages in order were: Phusachodu, Kikruma, Lekromi and Kami. Then using systematic sampling in villages with each a random start, 20 households were selected for interviewing the household member especially women members [12] responsible for cooking and serving to members using pre-tested structured schedules and questionnaires. Information on household demography, food basket, primary occupation, household income, food consumption, expenditure on inputs in terms of cost, food diversity, storage, children and old members' nutrition etc. were drawn. The food status of each individual member was difficult to assess from the study as households food security does not guarantee food security for all its members because of asymmetrical intra-household distribution of the food based on the needs of each individual member of a household [1].

\subsection{Food Security Indicators}

The cross section data collected from household were summarized and six components were derived thereof as discussed below:

\subsubsection{HDDS}

The HDDS is an indication of economic access to food items which require household resources. The Household Dietary Diversity Score (HDDS) used by the UN Food and Agriculture Organization and USAID [10,11] to understand diversity of food eaten recalled by respondents for the previous day of survey. Kennedy et al., [19,20], developed guidelines to calculate the HDDS and the Women's Dietary Diversity Score (WDDS) and compared it with other indicator namely Food Consumption Score for comparing their performance towards food security assessment and surveillance.

In the present study in Phek district, $\operatorname{HDDS}_{\mathrm{p}}$ was calculated as sum of diverse food groups consumed (amount) by household along with the level of nutritional importance of each food item categories identified in local aspect. Weighted nutritional importance on food groups was defined as the reverse ranking of importance held by respondents i.e., higher rank represents high weight and vice versa, and it was considered because similar diet diversity using conventional method was expected in remote rural locations. Finally, the scale was transformed to standard normal distribution ( $z$ component) for further algebraic requirements.

$$
x_{j}^{H D D S_{P}}=1 / k_{j} \sum_{i=1}^{m} w_{i} f_{i j}
$$

Where, $x_{j}^{{ }^{H D D S} P}=$ Household Diet Diversity Score of $j^{\text {th }}$ household in Phek district; 
$k_{j}=$ household size of $j^{\text {th }}$ household for $j=1,2, \ldots, n$;

Number of food groups $i=1,2, \ldots . . m$

$w_{i}$ is weight assigned to each food group;

$f_{i j}$ is amount/expense of different food group consumed by $j^{\text {th }}$ household and

$z_{j}^{H D D S_{P}}$ is the standard normal distributed variable of $x_{j}^{H D D S_{P}}$.

Aspect of diverse food groups locally grown or available is more important as diet diversity is mostly observed in urban places due to economic access whereas rural areas are more or less homogeneous in diet diversity.

\subsubsection{FCS}

The Food Consumption Score (FCS) is a specific type of weighted dietary diversity index used primarily by the World Food Programme [37]. Traditionally age-wise per-capita caloric intake was considered as food security measurement criteria for access to food at the household level, and measure of nutritional status were considered at the individual level $[7,15,34]$ but it was observed to underestimate the prevalence of food insecurity $[7,17]$. Food Consumption Score (FCS) is a food frequency measure developed by the World Food Programme (WFP) that is based on weighted dietary diversity, food frequency, and relative nutritional importance of different food groups.

In the present study, due to limitation of common dietary diversity and similar food groups available in the region, $\mathrm{FCS}_{\mathrm{P}}$ was calculated as per household member weekly food expense on different food groups during the week of correspondence, and the result transformed to standard normal form.

$$
x_{j}^{F C S_{P}}=1 / k_{j} \sum_{i=1}^{m} e_{i j}
$$

Where, $x_{j}^{F C S_{P}}=$ Food Consumption Score of $j^{\text {th }}$ household; $k_{j}=$ household size of $j^{\text {th }}$ household for $j=1,2, \ldots, n$;

Number of food groups $i=1,2, \ldots . . m$;

$e_{i j}$ is weekly expenses towards each $i^{\text {th }}$ food group incurred by $j^{\text {th }}$ household; and

$z_{j}^{F C S_{P}}$ is the standard normal distributed variable of $x_{j}^{F C S_{P}}$.

\subsubsection{CSI}

The Coping Strategy Index (CSI), a tool developed by the World Food Programme, is a weighted score that study the frequency and severity of coping strategies during food crisis. It is measure of consumption behavior which measures food security indirectly, and is based on frequency and severity of household behavior during low food or less money to buy food during 30 days period [22].

In present context, almost all households were observed to have farmland, livestock and vegetable and fruit trees although in varying capacity. In addition, various consumable plants leaves, game meat, wild fruits and insects as food were found common but immeasurable among households as coping strategies. Therefore, $\mathrm{CSI}_{P}$ was calculated based on different weekly food possessions per household member for food groups like livestock, cereal or millet crops, vegetables and fruits. Proportion of monthly savings to gross earnings and knowledge level on nutrition, occupation and literacy were considered as strategy for $\mathrm{CSI}_{\mathrm{P}}$ calculation. Finally, the scale was transformed to standard normal distribution (z component) for further algebraic requirements.

$$
x_{j}^{C S I} P=\left(\frac{1}{k_{j}} \sum_{t=1}^{s} l_{t j}\right)_{j}+S_{j} / G I_{j}
$$

Where, $x_{j}^{C S I_{P}}=$ Coping Strategy Index of $j^{\text {th }}$ household; $k_{j}=$ household size of $j^{\text {th }}$ household for $j=1,2, \ldots, n$;

$l_{t j}$ is the score for each $t$ strategy adopted by $j^{\text {th }}$ household for $t=1,2, \ldots s$;

$S_{j}$ is monthly monetary savings (Rs.) of $j^{\text {th }}$ household; $G I_{j}$ is Gross Monthly Income (Rs.) of $j^{\text {th }}$ household and $z_{j}^{C S I_{P}}$ is the standard normal distributed variable of $x_{j}^{C S I_{P}}$.

\subsubsection{SAFS}

This Self assessed food security (SAFS) includes selfassessments of current food status in a recent recall period and the change in livelihood status over a longer period of time. $\mathrm{SAFS}_{\mathrm{P}}$ being very subjective in nature it was calculated as inverse of sum of all weighted constraints identified by respondents and the result transformed to get standard normal form. The constraints were ranked by respondents as hindrance to them for fulfilling aspired food security and better living.

$$
x_{j}^{S A F S_{P}}=\left(\frac{1}{\sum_{n=1}^{c} w_{n}^{\prime} A_{n j}}\right)
$$

Where, $x_{j}^{S A F S_{P}}=$ Self Assessment of Food Security score of $j^{\text {th }}$ household;

$k_{j}=$ household size of $j^{\text {th }}$ household for $j=1,2, \ldots, n$;

$A_{n j}$ is the score of $n^{\text {th }}$ constraints perceived by $j^{\text {th }}$ household for $n=1,2, \ldots c$;

$w_{n}^{\prime}$ is weight on $n^{\text {th }}$ constraints (based on perception of respondents in the region);

$z_{j}^{S A F S_{P}}$ is the standard normal distributed variable of $x_{j}^{S A F S_{P}}$.

\subsubsection{HFIAS}

The Household Food Insecurity Access Scale (HFIAS) developed by the USAID was used to measure food security having nine low food status occurrence questions with responses 'yes' or 'no' and another set of corresponding nine questions on frequency-of-occurrence during last 30 days of recall [7]. The HFIAS measures insufficient quality and quantity of food, as well as anxiety over insecure access to food or market. HFIAS captures a mix of sufficiency and psychological factors.

In the study, HFIAS $_{\mathrm{P}}$ was calculated as simply ratio of monthly food expenditure to total earnings and the result transformed to get standard normal form. Since the questions for HFIAS was tested to be ineffective in eliciting proper response from respondents during pilot survey, the method of estimating the proportion of expenditure on food of the total household income considering the "propensity of people closer to the edge of poverty when they spend a greater proportion of their income on food" was accepted here. 


$$
x_{j}^{\operatorname{HFIAS}_{P}}=\frac{\sum_{i=1}^{m} E_{i j}}{G I_{j}}
$$

Where, $x_{j}^{\text {HFIAS }_{P}}=$ Household Food Insecurity Access Scale of $j^{\text {th }}$ household;

$k_{j}=$ household size of $j^{\text {th }}$ household for $j=1,2, \ldots, n$;

Number of food groups $i=1,2, \ldots . . m$;

$E_{i j}$ is monthly expenses towards each $i^{\text {th }}$ food group incurred by $j^{\text {th }}$ household

$G I_{j}$ is Gross Monthly Income (Rs.) of $j^{\text {th }}$ household

$z_{j}^{\text {HFIASP }_{P}}$ is the standard normal distributed variable of $x_{j}^{H^{H F I A S} P}$.

\subsubsection{HHS}

Household Hunger Scale (HHS) is a behavioral measure for measuring more-severe behaviors of households to food insecurity. The scale focuses on identifying severe hunger levels in households for cross-cultural comparison developed by USAIDS under FANTA project $[2,8]$. It was derived from similar methodology of HFIAS for cross cultural use and it is referred to as an "experiential" or "perception-based" method of collecting data. HFIAS measurement tool consists of nine food limitation occurrence and nine frequency-of-occurrence questions, where as HHS tool consists of last three questions of occurrence followed by frequency of occurrence questions representing absolutely no food and whole day and night hunger during 30 days period. Reference [32] also gave importance to national food security with balance food supply and demand, not necessarily distribution, at an acceptable price. They underlined inadequate resources responsible for food insecurity.

In the local situation, severe hunger was not observed for any household hence $\mathrm{HHS}_{\mathrm{P}}$ was calculated through weekly food demand supply gap. The household demand was calculated from recommended nutrition chart available from National Institute of Nutrition, Hyderabad. The gap was calculated for each household and then measuring average member of a household facing the gap. And the result obtained was transformed to get standard normal form.

$$
x_{j}^{H H S_{P}}=1 / k_{j} \sum_{i=1}^{m} g_{i j}
$$

Where, $x_{j}^{H H S_{P}}=$ Household Hunger Score of $j^{\text {th }}$ household; $k_{j}=$ household size of $j^{\text {th }}$ household for $j=1,2, \ldots, n$;

Number of food groups $i=1,2, \ldots . . m$;

$g_{i j}$ is weekly food demand-supply gap (kg) in $i^{\text {th }}$ food group faced by $j^{\text {th }}$ household;

$z_{j}^{H H S_{P}}$ is the standard normal distributed variable of $x_{j}^{H H S_{P}}$

\subsubsection{FSI}

Food Security Index $\left(\mathrm{FSI}_{\mathrm{P}}\right)$ for Phek district was calculated with concept of difference between minimum of four food security measurements and maximum of two food insecurity measurements. It is developed in order to empirically measure and classify each household on the path to food security.

$$
\begin{aligned}
x_{j}^{F S I_{P}}= & \operatorname{Min}\left(z_{j}^{F C S_{P}}, z_{j}^{H D D S_{P}}, z_{j}^{C S I_{P}}, z_{j}^{S A F S_{P}}\right) \\
& -\operatorname{Max}\left(z_{j}^{H F I A S_{P}}, z_{j}^{H H S_{P}}\right)
\end{aligned}
$$

Where, $x_{j}^{F S I_{P}}=$ Food Security Index of $j^{\text {th }}$ household; $z_{j}^{F C S_{P}}$ is standard normal score of $\mathrm{FCS}_{\mathrm{P}}$;

$z_{j}^{H D D S_{P}}$ is standard normal score of HDDS $\mathrm{P}_{\mathrm{P}}$;

$Z_{j}^{C S I_{P}}$ is standard normal score of $\mathrm{CSI}_{\mathrm{P}}$;

$z_{j}^{S A F S_{P}}$ is standard normal score of $\mathrm{SAFS}_{\mathrm{P}}$;

$z_{j}^{H F I A S_{P}}$ is standard normal score of HFIAS $\mathrm{p}$; and

$z_{j}^{H H S_{P}}$ is standard normal score of HHS.

Statistical analysis of the indicators using one-way ANOVA was adopted for statistical comparison of mean. Pearson's Correlation analysis was undertaken to study degree and direction of linear relationship among the indicators developed as well as with other socio-economic characters.

\section{Results and Discussion}

\subsection{Food Possession and Consumption}

Under this section food basket, household food possession (own production and purchased), expenditure on various food items, etc are discussed to find out the status of weekly food availability. Higher proportion of own produce was considered with more importance. Table 1 represented the food basket prepared from the responses of 80 sample households from two blocks of Phek district. The table gives the different food items that were locally available in the villages covered.

Table 1. Food Basket of sample households in Phek district

\begin{tabular}{|l|l|}
\hline Cereals & Rice, Maize, Millets etc. \\
\hline Pulses & $\begin{array}{l}\text { Lentil, Naga Dal, Pea, Beans, French beans, Cow pea } \\
\text { etc. }\end{array}$ \\
\hline Vegetables & $\begin{array}{l}\text { Cabbage, Potato, Chilli, Ginger, Tomato, Chow Chow, } \\
\text { Mustard leaf etc. }\end{array}$ \\
\hline Fruits & Guava, Peach, Plum, Banana, Kiwi, Apple etc \\
\hline Meat & Pork, Beef, Chicken, Fish \\
\hline Others & Egg, Milk, Oats, Sugar, Tea etc. \\
\hline Wild Edibles & $\begin{array}{l}\text { Wild vegetables, Wood worms, Mushrooms, Mollusc } \\
\text { (Snail), Crab etc. }\end{array}$ \\
\hline
\end{tabular}

Table 2 represents nutrition uptake of average household which indicated eight food groups consumed by households. Small family size with maximum of four members, medium families with 5 to 7 members and large families had minimum of eight household members were category of household size.

The eight food groups identified from the region were Cereals (Rice), Cereals (Maize, millets), Vegetables, Fruits, Milk, Egg, Fish and Meat. The energy consumed by average family belonging to three family sizes were calculated in kilocalorie per day using nutritional chart of National Institute of Nutrition, Hyderabad, India. Highest consumption was of cereals (staple food) and the lowest was of milk. It was observed that as family size increased, the consumption of each item also increased with a steady rate. 
Table 2. Average household food consumption and energy (kcal/day) up take

\begin{tabular}{|c|c|c|c|c|c|c|c|c|c|}
\hline $\begin{array}{c}\text { Family size } \\
\text { (members) }\end{array}$ & $\begin{array}{c}\text { Average } \\
\text { kcal/day }\end{array}$ & $\begin{array}{c}\text { Cereals (Rice) } \\
\text { kg/week }\end{array}$ & $\begin{array}{c}\text { Cereals (Maize, } \\
\text { millets) kg /week }\end{array}$ & $\begin{array}{c}\text { Vegetables } \\
\text { (kg/week) }\end{array}$ & $\begin{array}{c}\text { Fruits } \\
(\mathrm{kg} / \text { week) }\end{array}$ & $\begin{array}{c}\text { Milk } \\
\text { (g/week) }\end{array}$ & $\begin{array}{c}\text { Egg } \\
\text { (piece/week) }\end{array}$ & $\begin{array}{c}\text { Fish } \\
(\mathrm{kg} / \mathrm{month})\end{array}$ & $\begin{array}{c}\text { Meat } \\
(\mathrm{kg} / \mathrm{week})\end{array}$ \\
\hline Small $(\leq 4)$ & 3.52 & 8.77 & 1.27 & 7.69 & 3.54 & 292.31 & 4.69 & 1.27 & 1.27 \\
\hline Medium (5-7) & 4.23 & 10.45 & 1.51 & 8.42 & 4.02 & 340.57 & 5.42 & 1.51 & 1.51 \\
\hline Large ( $\geq 8)$ & 5.93 & 14.93 & 2.14 & 10.93 & 5.29 & 428.57 & 7.36 & 1.86 & 2.14 \\
\hline Overall & 4.41 & 10.96 & 1.58 & 8.74 & 4.16 & 348.13 & 5.64 & 1.53 & 1.58 \\
\hline
\end{tabular}

Reference [3] considered 'utilization' a pillar of food security, and the study showed that drinking water and sanitation facilities in the villages were very good since every household had access to tap water and toilet facility.

\subsection{Six Components of Household Food Security}

Six components of food security were $\mathrm{FCS}_{\mathrm{P}}, \mathrm{HDDS}_{\mathrm{P}}$, $\mathrm{CSI}_{\mathrm{P}}$ and $\mathrm{SAFS}_{\mathrm{P}}$ as food security measurement scores, and $\mathrm{HHS}_{\mathrm{P}}$ and HFIAS $\mathrm{P}_{\mathrm{P}}$ were measures of food insecurity score. Overall Food Security Index $\left(\mathrm{FSI}_{\mathrm{P}}\right)$ was calculated with concept of difference between minimum of four food security measurements and maximum of two food insecurity measurements. Table 3 showed the six dimensions of food security and overall food security index prepared from the six dimensions.

Using analysis of variance (ANOVA) for comparing three family sizes under study showed that all indicators were significant at $5 \%$ level of significance. Small family sizes were observed to be more food secure compared to medium or large family sizes indicating size and food security are negatively related [18,27].

Four sample villages belonging to two blocks were also analyzed using ANOVA to study significant difference among villages towards the indicators (Table 4). Since the block Kikruma was farther from Pfutsero town (distance of 8 to $12 \mathrm{~km}$ ) compared to Pfutsero block (distance of 4 to $5 \mathrm{~km}$ from town) it was expected that food security indicators would show difference among villages as rural area households inability to access sufficient food due to faraway markets and limited transportation [26].

However, only Coping Strategy Index $\left(\mathrm{CSI}_{\mathrm{P}}\right)$ showed significant difference (Table 4) among villages with Phusachodu and Kikruma villages in Kikruma block were statistically at par but Phusachodu village had significantly lower $\mathrm{CSI}_{\mathrm{P}}$ than Kami and Lekromi villages of Pfutsero block. It indicated that the villages that are closer to regular market and larger town had better Coping Strategies for food.

Reference [25] assessed inter-correlations among the seven indicators to analyze whether the different measures detected similar or different dimensions of food insecurity. In the present study, correlation matrix (Table 5) of six indicators and inter-correlation with Food Security Index developed from six indicators of food security measurement shows that almost all indicators were significant dimensions towards FSI p.

The FSI $_{P}$ score was observed to be significantly linked with the explanatory variables like household size and household income indicating better income from various sources help households avoid food insecurity [21]. Larger household size was negatively significant correlated with Food Security Index (Table 6). The FSI score was observed to be negatively significant linked with household size and positively significant with household monthly income.

Table 3. Comparison of food security/insecurity based on family size categories

\begin{tabular}{|c|c|c|c|c|c|c|c|}
\hline Family size & $\mathrm{FCS}_{\mathrm{P}}$ & $\mathrm{HDDS}_{\mathrm{P}}$ & $\mathrm{HHS}_{\mathrm{P}}$ & $\mathrm{CSI}_{\mathrm{P}}$ & HFIAS $_{\mathrm{P}}$ & SAFS $_{P}$ & Food security Index $\left(\mathrm{FSI}_{\mathrm{P}}\right)$ \\
\hline Small & 1.051 & 1.107 & -1.045 & 1.609 & 0.025 & 0.081 & -0.362 \\
\hline Medium & -0.093 & -0.119 & 0.144 & -0.130 & -0.054 & 0.051 & -1.239 \\
\hline Large & -0.618 & -0.570 & 0.415 & -0.991 & 0.186 & -0.274 & -2.125 \\
\hline $\operatorname{SEm}( \pm)$ & 0.357 & 0.354 & 0.365 & 0.258 & 0.412 & 0.411 & 0.430 \\
\hline$C D(p=0.05)$ & 1.156 & 1.145 & 1.179 & 0.834 & NS & NS & 1.391 \\
\hline
\end{tabular}

SEm: Standard error of Mean; CD: Critical Difference; NS: Non Significant at $\mathrm{p}=0.05$.

Table 4. Comparison of food security/insecurity based on villages

\begin{tabular}{|c|c|c|c|c|c|c|c|}
\hline Villages & $\mathrm{FCS}_{\mathrm{P}}$ & $\mathrm{HDDS}_{\mathrm{P}}$ & $\mathrm{HHS}_{\mathrm{P}}$ & $\mathrm{CSI}_{\mathrm{P}}$ & HFIAS $_{P}$ & SAFS $_{P}$ & Food security Index $\left(\mathrm{FSI}_{\mathrm{P}}\right)$ \\
\hline Phusachodu & -0.310 & -0.255 & 0.209 & -0.441 & 0.171 & 0.126 & -1.599 \\
\hline Kikruma & -0.064 & 0.067 & -0.212 & -0.292 & 0.227 & -0.202 & -1.292 \\
\hline Kami & 0.276 & 0.056 & 0.205 & 0.415 & 0.022 & -0.032 & -1.351 \\
\hline Lekromi & 0.093 & 0.135 & -0.203 & 0.322 & -0.419 & 0.101 & -0.827 \\
\hline $\operatorname{SEm}( \pm)$ & 0.222 & 0.225 & 0.223 & 0.211 & 0.220 & 0.226 & 0.256 \\
\hline$C D(p=0.05)$ & NS & NS & NS & 0.684 & NS & NS & NS \\
\hline
\end{tabular}

SEm: Standard error of Mean; CD: Critical Difference; NS: Non Significant at $\mathrm{p}=0.05$. 
Table 5. Correlation matrix of measurements of food security/insecurity with FSI

\begin{tabular}{|l|c|c|c|c|c|c|c|}
\hline & FCS $_{\mathrm{P}}$ & HDDS $_{\mathrm{P}}$ & HHS $_{\mathrm{P}}$ & CSI $_{\mathrm{P}}$ & HFIAS $_{\mathrm{P}}$ & SAFS $_{\mathrm{P}}$ & FSI $_{\mathrm{P}}$ \\
\hline FCS $_{\mathrm{P}}$ & 1.00 & & & & & & \\
\hline HDDS $_{\mathrm{P}}$ & $0.93^{* *}$ & 1.00 & & & & & \\
\hline HHS $_{\mathrm{P}}$ & $-0.57^{* *}$ & $-0.80^{* *}$ & 1.00 & & & & \\
\hline CSI $_{\mathrm{P}}$ & $0.58^{* *}$ & $0.64^{* *}$ & $-0.61^{* *}$ & 1.00 & & & \\
\hline HFIAS $_{\mathrm{P}}$ & $0.54^{* *}$ & $0.46^{* *}$ & $-0.16^{\mathrm{NS}}$ & $-0.16^{\mathrm{NS}}$ & 1.00 & & \\
\hline SAFS $_{\mathrm{P}}$ & $0.17^{\mathrm{NS}}$ & $0.22^{*}$ & $-0.20^{\mathrm{NS}}$ & $0.17^{\mathrm{NS}}$ & $0.11^{\mathrm{NS}}$ & 1.00 & \\
\hline FSI $_{\mathrm{P}}$ & $0.20^{\mathrm{NS}}$ & $0.36^{* *}$ & $-0.57^{* *}$ & $0.58^{* *}$ & $-0.43^{* *}$ & $0.40^{* *}$ & 1.00 \\
\hline
\end{tabular}

${ }^{*}$ Significant at $\mathrm{p}=0.05$ and ${ }^{* *}$ Significant at $\mathrm{p}=0.01 ; \mathrm{NS}=$ Non-significant.

Table 6. Correlation of socio-economic variables with FSI $_{P}$

\begin{tabular}{|l|c|c|c|c|}
\hline & HH size & HH Income & HH Expense \\
\hline HH size & 1.000 & & \\
\hline HH Income (Rs.) & 0.103 & 1.000 & \\
\hline HH Expense (Rs.) & 0.182 & $0.888^{* *}$ & 1.000 \\
\hline FSI $_{\mathrm{P}}$ score & $-0.496^{* *}$ & $0.226^{*}$ & 0.194 \\
\hline
\end{tabular}

* Significant at $\mathrm{p}=0.05$ and ${ }^{* *}$ Significant at $\mathrm{p}=0.01$; NS= Non-significant.

\section{Summary and Conclusion}

The study on food security indicators highlighted the need for alternative methodology relevant to local situations. The indicator based on self assessment and perceived constraints to food security $\left(\mathrm{SAFS}_{\mathrm{P}}\right)$ was more homogenous with lower coefficient of variation at 3.60\% hence not much relevant to classify food insecure households. The component HFIAS $_{\mathrm{P}}$ based on proportion of food expenses to total household income was observed to have higher coefficient of variation at $47 \%$ indicating more relevant to classification of households and comparison. Other four components had coefficient of variation ranging from 26 to 39\% indicating its relevance to the region subjectively. It was observed from the study that family size and primary occupation were statistically relevant to classify household food security level at intra-village consideration. At village level comparison, it was the distance and connectivity with regular market that make the difference between $\mathrm{CSI}_{P}$ of the villages.

Thus it can be concluded the need for localized structured interview schedules for households and indicators suitable for the village community for consistency and reliability of information on food status. The relevance of community and unique landownership pattern (Art. 371(a) of The Constitution of India [31]) in the state of Nagaland overwhelmed the household security measurement, so the need of food security at village or community was felt necessary. The presence of institutions like cooperatives, social and religious institutions have been observed to play great psychological and physical role in improving food status of the residents. Role of Government in food security was inadequately represented in the indicators as many social welfare schemes such as Food Security Act, Mid-Day Meal, Integrated Child Development Services, etc. were concurrently running with focus on specific target low income population. Also, food preference, food possession, availability and purchasing cycle along with stable distribution system, law and order, suitable institutional structures, government policies, business and the market have great influence on food security at household level [14,28].

\section{Acknowledgements}

The present study is a part of M.Sc.(Ag.) in Agricultural Economics research work. For the study we sincerely acknowledge the support of Nagaland University and the respondents in our endeavor to understand indicators of food security.

\section{References}

[1] Andersen, P. 2009. Food security: definitions and measurement. Food security. 1(1): 5-7.

[2] Ballard, T., Swindale, A., Coates J. and Deitchler, M. 2011. Household Hunger Scale: Indicator definition and measurement guide Washington DC, Food and Nutrition Technical Assistance Project-2 Bridge.

[3] Barrett C. B. 2010. Measuring Food Insecurity. Science 327, 825-828

[4] Barrett, C. B. (Ed.). 2013. Food Security \& Sociopolitical Stability. Oxford: Oxford University Press.

[5] Candel, J.J.L. 2014. Food security governance: a systematic literature review, Food Security, 6, 585-601.

[6] Coates, J., Swindale, A. and Bilinsky, P. 2006. Household Food Insecurity Access Scale (HFIAS) for Measurement of Household Food Access: Indicator Guide (v. 2). Washington, D.C.: Food and Nutrition Technical Assistance, Academy for Educational Development.

[7] Coates, A., Swindale, A. and Bilinsky, P. 2007. Household food insecurity access scale for measurement of food access: indicator guide (v. 3). Washington, DC: Food and Nutrition Technical Assistance Project.

[8] Deitchler, M., Ballard, T., Swindale, A. and Coates J., 2011. Introducing a simple measure of household hunger for cross cultural use. Technical note 12. Washington DC, FANTA Project-2. 
[9] ELCSA Scientific Committee. 2012. Escala Latinoamericana y Caribena de Seguridad Alimentaria (ELCSA): Manual de Uso y Aplicaciones. Rome, UN Food and Agricultural Organisation.

[10] FANTA (Food and Nutrition Technical Assistance). 2006. Food security. http://www.fanta.com Date of access: 1st July 2017.

[11] FAO (Food and Agriculture Organisation). 2010. The state of food insecurity in the world: addressing food insecurity in protracted crisis.

[12] FAO (Food and Agriculture Organisation). 2011. Guidelines for measuring household and individual dietary diversity. Rome: FAO.

[13] FAO (Food and Agriculture Organisation). 2011. Gender: Food and Agriculture Programme Organisation programme. http://www.fao.org/gender/gender-home/genderprogramme/gender-food/en/ Accessed on 27 July 2017.

[14] Hadley, C. 2011. The three pillars of food insecurity: getting to the guts of utilization. http://www.foodantro.com/2011/05/24/thethree-pillars-of-food-insecurity-getting-to-the-guts-of-utilizatio Date of access: 25 July 2017

[15] Hoddinott, J. \& Yohannes, Y. 2002. Dietary diversity as a food security indicator. Washington, DC: International Food Policy Research Institute.

[16] IFPRI (International Food Policy Research Institute). 2006. Review and Validation of Dietary Diversity, Food Frequency and Other Proxy Indicators of Household Food Security. Rome: International Food Policy Research Institute.

[17] IFPRI (International Food Policy Research Institute). 2008. Validation of Food Frequency and Dietary Diversity as Proxy Indicators for Household Food Security. Report submitted to WFP. Washington DC: IFPRI.

[18] Jacobs, P. 2009. Identifying targets for household food security in South Africa. Pretoria: Human Science Research Council.

[19] Kennedy, G., Ballard, T. and Dop, M. 2011. Guidelines for measuring household and individual dietary diversity, Nutrition and Consumer Protection Division, Food and Agriculture Organization of the United Nations.

[20] Kennedy, G, Berardo A, Papavero C, Horjus P, Ballard, Dop M, Delbaere J, Brouwer I. 2010. Proxy measures of household food consumption for food security assessment and surveillance: Comparison of the household dietary diversity and food consumption scores. Public Health Nutrition 13, 2010-2018. https://www.cambridge.org/core/terms. Accessed on 28 July 2017.

[21] Maxwell, S. and Frankenberger TR.1992. Household food security: Concepts, Indicators, measurements. A technical review. New York and Rome: UNICEF/ International Fund for Agricultural Development.

[22] Maxwell, D. and Caldwell, R. 2008. The Coping Strategies Index: A tool for rapid measurement of household food security and the impact of food aid programs in humanitarian emergencies Field Methods Manual. http://documents.wfp.org/stellent/groups/public/documents/manua l_guide_proced/wfp211058.pdf. Accessed on 28th July 2017.

[23] Maxwell, D., Caldwell, R. and Langworthy, M. 2008. Measuring Food Insecurity: Can an Indicator Based on Localized Coping Behaviors Be Used to Compare Across Contexts? Food Policy. 33 (6): 533-540.

[24] Maxwell, D. 1996. Measuring Food Insecurity: The Frequency and Severity of Coping strategies. Food Policy. 21 (3): 291-303.

[25] Maxwell, Daniel, Jennifer Coates, and Bapu Vaitla (2013). How Do Different Indicators of Household Food Security Compare? Empirical Evidence from Tigray. Feinstein International Center, Tufts University: Medford, USA.

[26] Nord, M., Andrews, M. \& Carlson. 2009. Household food security in the United States. Washington DC: U.S Department of Agriculture.

[27] Olayemi, A.O. 2012. Effects of family size on household food security in Osun State Nigeria. Asian Journal of Agriculture and Rural Development, 2(2): 136-141.

[28] Page, E.A. \& Redclif, M. 2002. Human security and the environment: international comparisons. Northampton: Edward Elgar Publishing, Inc.

[29] Smith, L.C., Aderman, H. \& Aduayom, D. 2006. Food security in Sub-Saharan Africa: new estimates from household expenditure surveys. Washington, DC: International Food Policy Research Institute.

[30] Statistical Handbook of Nagaland (2014), Directorate of Economics and Statistics, Published by DES, Government of Nagaland.

[31] The Constitution of India. 2015. http://lawmin.nic.in/olwing/coi/coi-english/coi-4March2016.pdf. (Accessed on 27 July 2017)

[32] Thomson, A. \& Metz, M. 1999. Implications of economic policy for food security. Rome: Food and Agriculture Organization of the United Nations.

[33] Webb, P., Coates, J., Fraongilo, EA., Swindale, A., \& Blinsky, P. 2006. Measuring household food insecurity: why it so important yet do difficult to do. Journal of Nutrition, 136(5): 1404-1408.

[34] Weismann, Doris, John Hoddinott, Noora-Lisa Aberman, and Marie T. Ruel. 2006. Review and Validation of Dietary Diversity, Food Frequency and Other Proxy Indicators of Household Food Security. Washington, D.C.: International Food Policy Research Institute.WFP 2009,

[35] Wright, L. and Gupta, P. 2017. Situational Nutritional Analysis of Idumishmi Tribes of Arunachal Pradesh, North-East India. Journal of Food Security, 5, (4): 113-119.

[36] Young, H. and Jaspars, Y. 2006. The Meaning and Measurement of Acute Malnutrition in Emergencies: A Primer for DecisionMakers. HPN Network Paper 56.

[37] WFP (World Food Programme). 2009. Food consumption analysis: Calculation and use of the food consumption score in food security analysis. VAM unit HQ Rome. 